Review Article

\title{
MUCOADHESIVE BUCCAL DRUG DELIVERY SYSTEM: REVIEW ARTICLE
}

\author{
MONALI SONAWANE ${ }^{1}$, DATTATREY SHINKAR ${ }^{2}$, RAVINDRASAUDAGAR ${ }^{3}$
}

\author{
1*Department of Pharmaceutics, 2Department of Quality Assurance, 3'Department of Pharmaceutical Chemistry, R. G. Sapkal College of \\ Pharmacy, Anjaneri, Nashik 422213, Maharashtra, India
}

Email: monalis03331@gmail.com

Received: 27 Jan 2017, Revised and Accepted: 20 Apr 2017

\begin{abstract}
The advantage of buccal drug delivery system over the conventional and systemic formulation majority. It helps enhance the bioavailability through bypassing the first-pass metabolism effect. The mucosal surface better absorption and prolong resident time. Bioadhesion can be defined as the phenomenon of interfacial molecular attractive force in midst of the surface of the biological substrate and the natural or synthetic polymers, which allows the polymers to adher to the biological surface for an extended period of time. Among the various transmucosal sites available, mucosa of the buccal cavity was found to be the most convenient and easily approachable site for the delivery of the therapeutic agent for both local and systemic delivery. This review also covers available marketed product as buccal drug delivery system and future aspects of buccal drug delivery system.
\end{abstract}

Keywords: Buccal drug delivey system, Anatomy and Physiology, Bioadhesion, Transmucosal dosage forms, Evaluation parameters

(C) 2017 The Authors. Published by Innovare Academic Sciences Pvt Ltd. This is an open access article under the CC BY license (http://creativecommons.org/licenses/by/4.0/) DOI: http://dx.doi.org/10.22159/ijcpr.2017v9i4.20960

\section{INTRODUCTION}

Oral drug delivery has been known for decades as the most widely utilized route of administration among all the routes that have been explored for the systemic delivery of drugs via various pharmaceutical products of different dosage forms. An ideal DDS should aid in the optimization of drug therapy by delivering an appropriate amount to the intended site and at a desired rate. By and large, a DDS may be employed for spatial placement (i.e., targeting a drug to a specific organ or tissue) or temporal delivery (i.e., controlling the rate of drug delivery to the target tissue) [1]. Transmucosal routes of drug delivery (i.e., the mucosal linings of the nasal, rectal, vaginal, ocular, and oral cavity) offer distinct advantages over peroral administration for systemic drug delivery13. These advantages include a possible bypass of first pass effect, avoidance of pre-systemic elimination within the GI tract, and, depending on the particular drug, a better enzymatic flora for drug absorption4. Though the nasal rectal, vaginal, and ocular mucosae all offer certain advantages, the poor patient acceptability associated with these sites renders them reserved for local applications rather than systemic drug administration [2-3]. The various transmucosal routes, buccal mucosa has excellent accessibility, an expanse of smooth muscle and relatively immobile mucosa, hence suitable for administration of retentive dosage forms. Direct access to the systemic circulation through the internal jugular vein bypasses drugs from the hepatic first pass metabolism leading to high bioavailability. Other advantages such as low enzymatic activity, suitability for drugs or excipients that mildly and reversibly damages or irritates the mucosa, painless administration, easy drug withdrawal, facility to include permeation enhancer/enzyme inhibitor or $\mathrm{pH}$ modifier in the formulation and versatility in designing as multidirectional or unidirectional release systems for local or systemic actions etc, opts buccal adhesive drug delivery systems as promising option for continued research [3]. Drug delivery across the oral mucosa can be divided into three different type.

Sublingual drug delivery, consisting of the administration through the membrane of the ventra surface of the tongue and the floor of the mouth.

Buccal drug delivery, consisting of the administration through the buccal mucosa, mainly composed of the lining of the cheeks and

Local drug delivery, consisting of the administration through all areas other than former two regions [4].
These site differs anatomically in their permeability to drugs, the rate of drug delivery, and ability to maintain a delivery system for a time required for drug release out of the delivery apparatus and into the mucosa [5].

\section{Buccal drug delivery}

The buccal mucosa lines the inner cheek, and buccal formulations are placed in the mouth between the upper gingivae (gums) and cheek to treat local and systemic conditions. The buccal route provides one of the potential routes for typically large, hydrophilic and unstable proteins, oligonucleotides and polysaccharides, as well as conventional small drug molecules. The oral cavity has been used as a site for local and systemic drug delivery [6].

\section{Buccal mucosa}

Amongst the various routes of drug delivery, oral route is perhaps the most preferred to the patient. However, peroral administration of drugs has disadvantages such as hepatic first pass metabolism and enzymatic degradation within the GI tract, that prohibit oral administration of certain classes of drugs especially peptides and proteins. Consequently, other absorptive mucosae are considered as potential sites for drug administration. Transmucosal routes of drug delivery (i.e., the mucosal linings of the nasal, rectal, vaginal, ocular, and oral cavity) offer distinct advantages over peroral administration for systemic drug delivery [7-8]. These advantages include a possible bypass of first pass effect, avoidance of pre-systemic elimination within the GI tract, and, depending on the particular drug, a better enzymatic flora for drug absorption4. Though the nasal rectal, vaginal, and ocular mucosa all offer certain advantages, the poor patient acceptability associated with these sites renders them reserved for local applications rather than systemic drug administration [7-9] the oral cavity is $100 \mathrm{~cm} 2$. One-third is the buccal surface, which is lined with an epithelium of about $0.5 \mathrm{~mm}$ thickness. The main role of the oral mucosa is the protection of tissue underlying. Lipid-based permeability barriers in epithelium layer protect the tissues from fluid loss and also from the attack of harmful environmental agents like microbial toxins, antigens, carcinogens, enzymes etc. Oral epithelium proliferation time is 5-6 d. The oral cavity is that area of mouth delineated by the lips, cheeks, hard palate, soft palate and floor of the mouth. The oral cavity consists of two regions. Outer oral vestibule which is bounded by cheeks, lips, teeth and gingival (gums). Oral cavity proper which extends from teeth and gums back to the faucets (which lead to pharynx) with the roof comprising the hard and soft palate. The tongue projects from the floor of the cavity $[10,11]$. 


\section{Functions of oral cavity [12]}

- It helps in chewing, mastication and mixing of food stuff.

- It is Helps to lubricate the food material and bolus.

- To identify the ingested material by taste buds of the tongue.

- To initiate the carbohydrate and fat metabolism.

- As a portal for intake of food material and water.

- To aid in speech and breathing process.

\section{Basement membrane}

Although the superficial layers of the oral epithelium represent the primary barrier to the entry of substances from the exterior, it is evident that the basement membrane also plays a role in limiting the passage of materials across the junction between epithelium and connective tissue. A similar mechanism appears to operate in the opposite direction. The charge on the constituents of the basal lamina may limit the rate of penetration of lipophilic compounds that can traverse the superficial epithelial barrier relatively easily [13].

\section{Mucus}

The epithelial cells of buccal mucosa are surrounded by the intercellular ground substance called mucus with the thickness varies from $40 \mu \mathrm{m}$ to $300 \mu \mathrm{m}$ [14]. Though the sublingual glands and minor salivary glands contribute only about $10 \%$ of all saliva, together they produce the majority of mucus and are critical in maintaining the mucin layer over the oral mucosa [15]. At buccal pH, mucus can form a strongly cohesive gel structure that binds to the epithelial cell surface as a gelatinous layer [16]. Mucus is composed chiefly of mucins and inorganic salts suspended in water. Mucins are a family of large, heavily glycosylated proteins composed of oligosaccharide chains attached to a protein core. Three-quarters of the protein core are heavily glycosylated and impart a gel-like characteristic tomucus. Mucins contain approximately 70-80\% carbohydrate, $12-25 \%$ protein and up to $5 \%$ ester sulphate [17].

\section{Saliva}

The mucosal surface has a salivary coating estimated to be $70 \mu \mathrm{m}$ thick [18], which act as a unstirred layer. Within the saliva, there is a high molecular weight mucin named MG1[19] that can bind to the surface of the oral mucosa so as to maintain hydration, provide lubrication, concentrate protective molecules such as secretory immunoglobulins, and limit the attachment of microorganisms. Several independent lines of evidence suggest that saliva and salivary mucin contribute to the barrier properties of oral mucosa [20]. The major salivary glands consist of lobules of cells that secrete saliva; parotids through salivary ducts near the upper teeth, submandibular under the tongue, and the sublingual through many ducts in the floor of the mouth. Besides these glands, there are 6001000 tiny glands called minor salivary glands located in the lips, inner cheek area (buccal mucosa), and extensively in other linings of the mouth and throat [21].

\section{Mechanism of bioadhesion}

The process of bioadhesion can be viewed as occurring in two steps. First intimate contact between the polymers and membrane followed by formation of bonds. The bonding occurs chiefly through both physical and mechanical bonds results from the entanglement of the adhesive material and the extended mucus chain.

\section{Novel transmucosal dosage forms}

The novel type buccal dosage forms include buccal adhesive patches, tablets, films, semisolids (ointments and gels) and powders [22].

\section{Patches and Films}

Patches consists of two laminates, with an aqueous solution of the adhesive polymer being cast onto an impermeable backing sheet, which is then cut into the required oval shape [23]. A novel mucosal adhesive film called "Zilactin"-consisting of an alcoholic solution of hydroxyl propyl cellulose and three organic acids. The film which is applied to the oral mucosal can be retained in place for at least $12 \mathrm{~h}$ even when it is challenged with fluids. E. g. buccal film of salbutamol.

\section{Buccal mucoadhesive tablets}

Mucoadhesive tablets are dry dosage forms and it is to be moistened prior to placing in contact with buccal mucosa [24]. It is double layer tablet, consisting of adhesive matrix layer of polyacrylic acid and hydroxypropyl, cellulose with an inner core of cocoa butter containing insulin and a penetration enhancer (sodium glycocholate).

\section{Semisolid preparations (Ointments and Gels)}

One of the original oral mucoadhesive delivery systems-"orabase"consists of finely ground pectin, gelatin and sodium carboxymethylcellulose dispersed in a poly (ethylene) and a mineral oil gel base, which can be maintained at its site of application for 15-150 min. Example: chitosan glutamate buccal hydrogel with local anaesthetics activity [25].

\section{Powders}

Beclomethasone and Hydroxypropyl cellulose in powder form when sprayed onto the oral mucosa of rats, a significant increase in the residence time relative to an oral solution is seen, and $2.5 \%$ of beclomethasone is retained on buccal mucosa for over $4 \mathrm{~h}$ [26].

\section{Buccal sprays}

Generex biotechnologies have been introduced insulin spray [27]. This technology is being used to develop a formulation for buccal delivery of insulin for the treatment of type- 1 diabetes Buccal spray delivers a mist of fine droplets onto mucosal membrane probably on to mucin layer. e. g. Estradiol sprays [28].

\section{Evaluation of buccal drug delivery systems \\ Surface pH [29]}

Buccal patches are left to swell for $2 \mathrm{hr}$ on the surface of an agar plate. The surface $\mathrm{pH}$ is measured by means of a $\mathrm{pH}$ paper placed on the surface of the swollen patch.

\section{Thickness measurements [30]}

The thickness of each film is measured at five different locations (centre and four corners) using an electronic digital micrometre.

\section{Swelling study [31]}

Weighed the buccal patches individually (W1), and placed separately in $2 \%$ agar gel plates, incubated at $37{ }^{\circ} \mathrm{C} \pm 1{ }^{\circ} \mathrm{C}$, and examined for any physical changes. At regular time intervals until 3 $\mathrm{h}$, patches are removed from the gel plates and excess surface water is removed carefully using the filter paper. The swollen patches are then reweighed (W2) and the swelling index (SI) were calculated using the following formula.

$$
\mathrm{SI}=\left(\mathrm{W}_{2}-\mathrm{W}_{1}\right) / \mathrm{W}_{1} \times 100
$$

\section{Folding endurance [32]}

Folding endurance can be done by folding the patches upto200 times with our breaking.

\section{Thermal analysis study}

Thermal analysis study is performed using differential scanning calorimeter (DSC).

\section{Morphological characterization [33]}

Morphological characters are studied by using scanning electron microscope (SEM).

\section{Water absorption capacity test}

Circular Patches, with a surface area of $2.3 \mathrm{~cm} 2$ are allowed to swell on the surface of agar plates prepared in simulated saliva $2.38 \mathrm{~g}$ Na2HPO4, $0.19 \mathrm{~g} \mathrm{KH2PO4,} \mathrm{and} 8 \mathrm{~g} \mathrm{NaCl}$ per liter of distilled water adjusted with phosphoric acid to $\mathrm{pH}$ 6.7), and kept in an incubator maintained at $37^{\circ} \mathrm{C} \pm 0.5^{\circ} \mathrm{C}$. At various time intervals $(0.25,0.5,1,2$, 3 , and $4 \mathrm{~h}$ ), samples are weighed (wet weight) and then left to dry 
for $7 \mathrm{~d}$ in a desiccators over anhydrous calcium chloride at room temperature then the final constant weights are recorded.

\section{Ex-vivo bioadhesion test}

A piece of gingival mucosa is tied in the open mouth of a glass vial, filled with phosphate buffer ( $\mathrm{pH}$ 6.8). This glass vial is tightly fitted into a glass beaker filled with phosphate buffer $\left(\mathrm{pH} 6.8,37^{\circ} \mathrm{C} \pm 1{ }^{\circ} \mathrm{C}\right)$ so it just touched the mucosal surface. The patch is stuck to the lower side of a rubber stopper with cyanoacrylate adhesive. Two pans of the balance are balanced with a $5 \mathrm{~g}$ weight. The $5 \mathrm{~g}$ weight is removed from the left-hand side pan, which loaded the pan attached with the patch over the mucosa. The balance is kept in this position for $5 \mathrm{~min}$ of contact time. The water is added slowly at 100 drops/min to the right-hand side pan until the patch detached from the mucosal surface.

\section{In vitro drug release}

The dissolution medium consisted of phosphate buffer $\mathrm{pH} 6.8$ maintaining a temperature at $37^{\circ} \mathrm{C} \pm 0.5^{\circ} \mathrm{C}$, with a rotation speed of 50 $\mathrm{rpm}$. The backing layer of the buccal patch is attached to the glass disk with the instant adhesive material. The disk is allocated to the bottom of the dissolution vessel. Samples $(5 \mathrm{ml})$ are withdrawn at predetermined time intervals and replaced with fresh medium. The samples filtered through whatman filter paper and analyzed for drug content after appropriate dilution in a UV spectrophotometer. The in vitro buccal permeation through the buccal mucosa (sheep and rabbit) is performed using Keshary Chien/Franz-type glass diffusion cell at 37 ${ }^{\circ} \mathrm{C} \pm 0.2{ }^{\circ} \mathrm{C}$. Fresh buccal mucosa is mounted between the donor and receptor compartments. The buccal patch is placed with the core facing the mucosa and the compartments clamped together. The donor compartment is filled with suitable buffer.

\section{Permeation study of buccal patch}

The receptor compartment is filled with phosphate buffer $\mathrm{pH} 6.8$, and the hydrodynamics in the receptor compartment is maintained by stirring with a magnetic bead at $50 \mathrm{rpm}$. Samples are withdrawn at predetermined time intervals and analyzed for drug content.

\section{Ex-vivo mucoadhesion time}

The ex-vivo mucoadhesion time performed after application of the buccal patch on freshly cut buccal mucosa (sheep and rabbit). The fresh buccal mucosa is tied on the glass slide, and a mucoadhesive patch is wetted with 1 drop of phosphate buffer $\mathrm{pH} 6.8$ and pasted to the buccal mucosa by applying a light force with a fingertip for 30 seconds. The glass slide is then put in the beaker, which is filled with $200 \mathrm{ml}$ of the phosphate buffer $\mathrm{pH} 6.8$, is kept at $37^{\circ} \mathrm{C} \pm 1{ }^{\circ} \mathrm{C}$. After 2 min, a 50 -rpm stirring rate is applied to simulate the buccal cavity environment, and patch adhesion is monitored for $12 \mathrm{~h}$. The time for changes in color, shape, collapsing of the patch and drug content is noted.

\section{Measurement of mechanical properties}

Mechanical properties of the films (patches) include tensile strength and elongation at break is evaluated using a tensile tester. Film strip with the dimensions of $60 \times 10 \mathrm{~mm}$ and without any visual defects cut and positioned between two clamps separated by a distance of 3 $\mathrm{cm}$. Clamps designed to secure the patch without crushing it during the test, the lower clamp held stationary and the strips are pulled apart by the upper clamp moving at a rate of $2 \mathrm{~mm} / \mathrm{sec}$ until the strip break. Force and elongation of the film at the point when the strip break is recorded. The tensile strength and elongation at break values are calculated using the formula. Where, M-is the mass in gm, g-is the acceleration due to gravity $980 \mathrm{~cm} / \mathrm{sec} 2$, B-is the breadth of the specimen in $\mathrm{cm}, \mathrm{T}$-is the thickness of specimen in $\mathrm{cm}$. Tensile strength $(\mathrm{kg} / \mathrm{mm} 2)$ is the force at break $(\mathrm{kg})$ per initial crosssectional area of the specimen $(\mathrm{mm} 2)$.

\section{Stability study in human saliva}

The stability study of optimized bilayered and multilayered patches is performed in human saliva. The human saliva is collected from humans (age 18-50 y). Buccal patches are placed in separate Petri dishes containing $5 \mathrm{ml}$ of human saliva and placed in a temperature controlled oven at $37^{\circ} \mathrm{C} \pm 0.2^{\circ} \mathrm{C}$ for $6 \mathrm{~h}$. At regular time intervals $(0$,
1, 2, 3, and $6 \mathrm{~h}$ ), the dose formulations with better bioavailability are needed.

\section{Animal models for permeability measurement}

The most commonly used animal models are dogs, rabbits, and pigs. A general criterion for selecting an in vivo animal model is the resemblance of the animal mucosa to the oral mucosa of human beings in both ultrastructure and enzyme activity, which represent the physical and metabolic barriers of the oral mucosa.

\section{CONFLICT OF INTERESTS}

\section{Declare none}

\section{REFERENCES}

1. Bhatt DA, Pethe AM. Mucoadhesive drug delivery systems: an overview. J Pharm Res 2010;3:1743-47.

2. Soyani AP, Chien YW. Systemic delivery of peptides and proteins across absorptive mucosae. Crit Rev Ther Drug Carrier Syst 1996;13:85-184.

3. HH Alur, TP Johnston, AK Mitra. Encyclopedia of pharmaceutical technology. In: J Superbrick, JC Boylan. Eds. Peptides and proteins: buccal absorption. Vol. 20. Marcel Dekker Inc, New York; 2001. p. 193-218.

4. Patel Mitul, Karigar Asif, Savaliya Pratik. Buccal drug delivery system. Int Res J Pharm 2011;2:4-11.

5. Khairnar GA, Sayyad FJ. Development of buccal drug delivery system based on mucoadhesive polymers. Int J Pharma Tech Res 2010;2:719-35.

6. Senel S, Kremer M, Nagy K, Squier C. Delivery of bioactive peptides and proteins across oral (buccal) mucosa. Curr Pharma Biotechnol 2001;2:175-86.

7. Aungst BJ, Rogers NJ. Shefter Buccal, sublingual and E. comparison of nasal, rectal, intramuscular insulin efficacy and the effects of a bile salt absorption promoter. J Pharmacol Exp Ther 1988;244:23-7.

8. Lee WE. Permeation enhancers for the nasal delivery of protein and peptide Ther Biopharm 1990;3:22-5.

9. Soyani AP, Chien YW. Systemic delivery of peptides and proteins across absorptive mucosae. Crit Rev Ther Drug Carrier Systems 1996;13:85-184.

10. Hooda R, Tripathi M, Kapoor K. A review an oral mucosal drug delivery system. Phrma Innovation 2012;1:14-21.

11. Siddaqui MDN, Garg G, Sharma PK. A short review on "A novel approach in oral fast dissolving drug delivery system and their patents". Adv Biol Res 2011;5:291-303.

12. Shidhaye SS. Mucoadhesive bilayered patches for administration of sumatriptan. AAPS Pharm Sci Tech 2008;9:909-16.

13. K Wolff, HJ Honigsmann. Langerhans cells in cell culture ultrastructural studies with thorotrast as a marker. J Ultrastruct Res 1971;36:176-90.

14. Allen. In: JG Forte. Ed. Handbook of physiology the gastrointestinal physiology-the gastrointestinal physiology, salivary, gastric and hepatobiliary secretions. Vol. III. American Physiological Society, Bethesda, MD; 1989. p. 359-82.

15. FS Rosen, BJ Bailey. Anatomy and physiology of salivary glands, Grand Rounds presentation, UTMB, Department of Otolaryngology; 2001.

16. RB Gandhi, JR Robinson. Bioadhesion in drug delivery. Indian J Pharm Sci 1988;50:145-52.

17. SE Harding, JM Creeth, AJ Rowe. In: A Chester, D Heinegard, A Lundblad, S Svenssion. Eds. Proceedings of the 7th International Glycoconjugates Conference Olsson Reklambyra, Sweden; 1983. p. 558-9.

18. LMC Collins, C Dawes. The surface area of the adult human mouth and thickness of the salivary film covering the teeth and oral mucosa. J Dent Res 1987;66:1300-2.

19. MJ Levine, PC Jones, RE Looms, MS Reddy, I Al-Hashimi, EJ Bergey. In: IC Mackenzie, CA Squierv, Dablesteen. Eds. Oral mucosal diseases: biology, etiology and therapy, laegeforeningens folag, Copenhagen; 1987. p. 7-9.

20. L Schenkels, TL Gururaja, MJ Levine. In: MJ Rathbone. Ed. Oral Mucosal Drug Delivery, Marcel Dekker, New York; 1996. p. 191-220. 
21. TC Kontis, ME Johns. Anatomy and physiology of salivary glands. In: Byron J Bailey. Ed. Head and Neck SurgeryOtolaryngology. 2nd edition. Lippincott_raven publishers, Philadelphia, PA; 1998. p. 531-9.

22. Zhang J. An in vivo dog model for studying recovery kinetics of the buccal mucosa permeation barrier after exposure to permeation enhancers apparent evidence of effective enhancement without tissue damage. Int J Pharm 1994;101:15-22.

23. Amir H Shojaei, Richard K Chang, Xiaodi Guo, Beth A Burnside, Richard A Couch. Systemic drug delivery via the buccal mucosal route. Pharm Technol 2001;51:70-81.

24. Thimmasetty J, Pandey GS, Sathesh Babu PR. Design and in vivo evaluation of carvedilol buccal mucoadhesive patches. Pak J Pharm Sci 2008;21:241-8.

25. Panigrahi L, Snigdha Pattnaik, Ghosal SK. Design and characterization of mucoadhesive buccal patches of diclofenac sodium. Indian J Pharm Sci 2005;67:319-26.

26. Edsman K. Pharmaceutical applications of mucoadhesion for the non-oral routes. J Pharm Pharmacol 2005;57:3-19.

27. Steward A. The effect of enhancers on the buccal absorption of hybrid (BDBB) alpha-interferon. Int J Pharm 1994;104:145-9.
28. Aungst BJ, Rogers NJ, Site dependence of absorption-promoting actions of laureth, na salicylate, Na2EDTA, Aprotin Doijad R, et al. Buccoadhesive drug delivery system of isosorbide dinitrate, formulation and evaluation. Indian J Pharm Sci 2006;68:744-8.

29. Edsman K. Pharmaceutical applications of mucoadhesion for the non-oral routes. J Pharm Pharmacol 2005;57:3-19.

30. Pillai S. Design and evaluation of buccal films of Isoxsuprine hydrochloride. Res J Pharm Biol Chem Sci 2010;1:158-64.

31. Alanazi FK. Formulation and physicochemical characterization of buccoadhesive films containing ketorolac. J Drug Delivery Sci Technol 2007;17:1-10.

32. Hirlekar RS, Kadam VJ. Design of buccal drug delivery system for poorly soluble drug. Asian J Pharm Clin Res 2009;2:49-53.

33. Gavin P Andrews, Thoma P-Laverty, David S Jones. Mucoadhesive polymeric platforms for controlled drug delivery. Eur J Pharm Biol Pharm 2009;71:505-18.

\section{How to cite this article}

- Monali Sonawane, Dattatrey Shinkar, Ravindrasaudagar. Mucoadhesive buccal drug delivery system: a review article. Int J Curr Pharm Res 2017;9(4):1-4. 